\title{
Potential of MRI in Radiotherapy Mediated by Small Conjugates and Nanosystems
}

\author{
Retna Putri Fauzia ${ }^{1}$, Antonia G. Denkova ${ }^{2}$ and Kristina Djanashvili ${ }^{1, *(1)}$ \\ 1 Department of Biotechnology, Delft University of Technology, Van der Maasweg 9, 2629 HZ Delft, \\ The Netherlands; r.p.fauzia@tudelft.nl \\ 2 Department of Radiation Science and Technology, Delft University of Technology, Mekelweg 15, \\ 2629 JB Delft, The Netherlands; a.g.denkova@tudelft.nl \\ * Correspondence: k.djanashvili@tudelft.nl; Tel.: +31-15-278-5092
}

Received: 6 April 2019; Accepted: 25 April 2019; Published: 30 April 2019

\begin{abstract}
Radiation therapy has made tremendous progress in oncology over the last decades due to advances in engineering and physical sciences in combination with better biochemical, genetic and molecular understanding of this disease. Local delivery of optimal radiation dose to a tumor, while sparing healthy surrounding tissues, remains a great challenge, especially in the proximity of vital organs. Therefore, imaging plays a key role in tumor staging, accurate target volume delineation, assessment of individual radiation resistance and even personalized dose prescription. From this point of view, radiotherapy might be one of the few therapeutic modalities that relies entirely on high-resolution imaging. Magnetic resonance imaging (MRI) with its superior soft-tissue resolution is already used in radiotherapy treatment planning complementing conventional computed tomography (CT). Development of systems integrating MRI and linear accelerators opens possibilities for simultaneous imaging and therapy, which in turn, generates the need for imaging probes with therapeutic components. In this review, we discuss the role of MRI in both external and internal radiotherapy focusing on the most important examples of contrast agents with combined therapeutic potential.
\end{abstract}

Keywords: theranostics; magnetic resonance imaging; contrast agents; relaxivity; gadolinium; iron oxide nanoparticles; ionizing radiation; radiosensitization; therapeutic radionuclides

\section{Introduction}

Radiotherapy (RT) has become an indispensable tool in oncology, representing non-surgical treatment by cytotoxic ionizing radiation with the ability to destroy cancerous cells. One of the main objectives of a successful treatment is an accurate delivery of a correct therapeutic dose to the target while avoiding radiation exposure of the surrounding healthy tissues. This requires careful delineation of tumor by detecting its extension as well as assessing morphology, physiology, and biochemistry prior to therapy. All this information is gathered typically within the radiotherapy treatment planning (RTP) practice, which basically includes collective efforts by radiation oncologists, physicians, and radiologists for determination of the appropriate RT procedure, be it application of external radiation beams, internal brachytherapy or prescription of internal radionuclide therapeutics. Modern medical imaging is a valuable aid for RTP, and for many years computed tomography (CT) was considered the most suitable imaging modality based on its accessibility and high precision in determination of geometrical target parameters necessary for accurate external irradiation, and tissue electron density for the dose calculation. However, its poor soft-tissue contrast is in many cases limiting the spatial accuracy, which is important for the correct determination of tumor margins, especially when cancers in the proximity to the vital organs are at stake. Another concern in external RT is patient misalignment as a result of internal motions, such as swallowing, respiration or muscle contraction/relaxation. Again, 
the insufficient depiction of soft-tissues in radiographic images forms a serious drawback that requires calling in of complementary imaging techniques.

Magnetic resonance imaging (MRI) overcomes the aforementioned limitations due to its superb temporal and spatial resolution, and excellent soft-tissue contrast. As a non-invasive imaging modality without implication of ionizing radiation, it relies on the observation of water molecule protons, based on their density and relaxation dynamics. Altogether, these parameters lead to visualization of the differences in tissues by generation of either $T_{1^{-}}$(positive/bright) or $T_{2}$-weighted (negative/dark) contrast. Thereby, tailored MRI pulse-sequences enable various types of contrast for functional and volumetric assessment of tumors, with the possibility for unlimited multiplanar image reconstruction. Furthermore, dynamic contrast-enhanced MRI offers a possibility to monitor the signal in a tumor over time with rapid ( \pm every $3 \mathrm{~s}$ ) $3 \mathrm{D}$-imaging using $T_{1}$-weighted sequences [1]. The methods for data acquisition in MRI allow for slice orientation in sagittal, coronal or any other convenient angle for better alignment with anatomy, compared to transaxial CT. Concerning assessment of functional tumor parameters, blood oxygenation level-dependent (BOLD) MRI can be used to visualize tumor hypoxia, which is one the predictors of patient response to radiotherapy [2]. From the instrumental point of view, systems integrating MRI and a linear accelerator are being developed and tested in the clinic with the goal to improve definition and geometrical calibration of tumors and to enable simultaneous irradiation $[3,4]$.

The lack of sensitivity of MRI can be circumvented by administration of contrast agents (CAs), which are typically either small paramagnetic Gd(III)- or Mn(II)-complexes or superparamagnetic iron oxide nanoparticles (SPIONs) that shorten $T_{1}$ or $T_{2}$ relaxation times of surrounding protons, respectively. The effectiveness of CAs is expressed in relaxivity $\left(r_{1}\right.$ or $\left.r_{2}\right)$, defined as the rate of increase of the corresponding relaxation time per $\mathrm{mM}$ of metal ion. The relaxivity enhancement is then either the result of dipolar interactions between the paramagnetic center and the protons in its vicinity, or perturbation of magnetic field around superparamagnetic center, which translates into the generation of high-resolution $T_{1}$ or $T_{2}$ contrast, respectively.

All these features substantiate the importance of MRI as a technique complementary to CT for its application in RTP [5] and open perspectives for this imaging modality to serve as a platform for new types of agents for combined imaging and therapy, called theranostics [6]. This review focuses on the role of MRI for different types of RT (Figure 1) and surveys the most important types of MRI CAs that have been developed to enhance the effects of external RT, enable monitoring of delivery and distribution of the internal radiotherapeutics, and evaluate the therapeutic outcome.

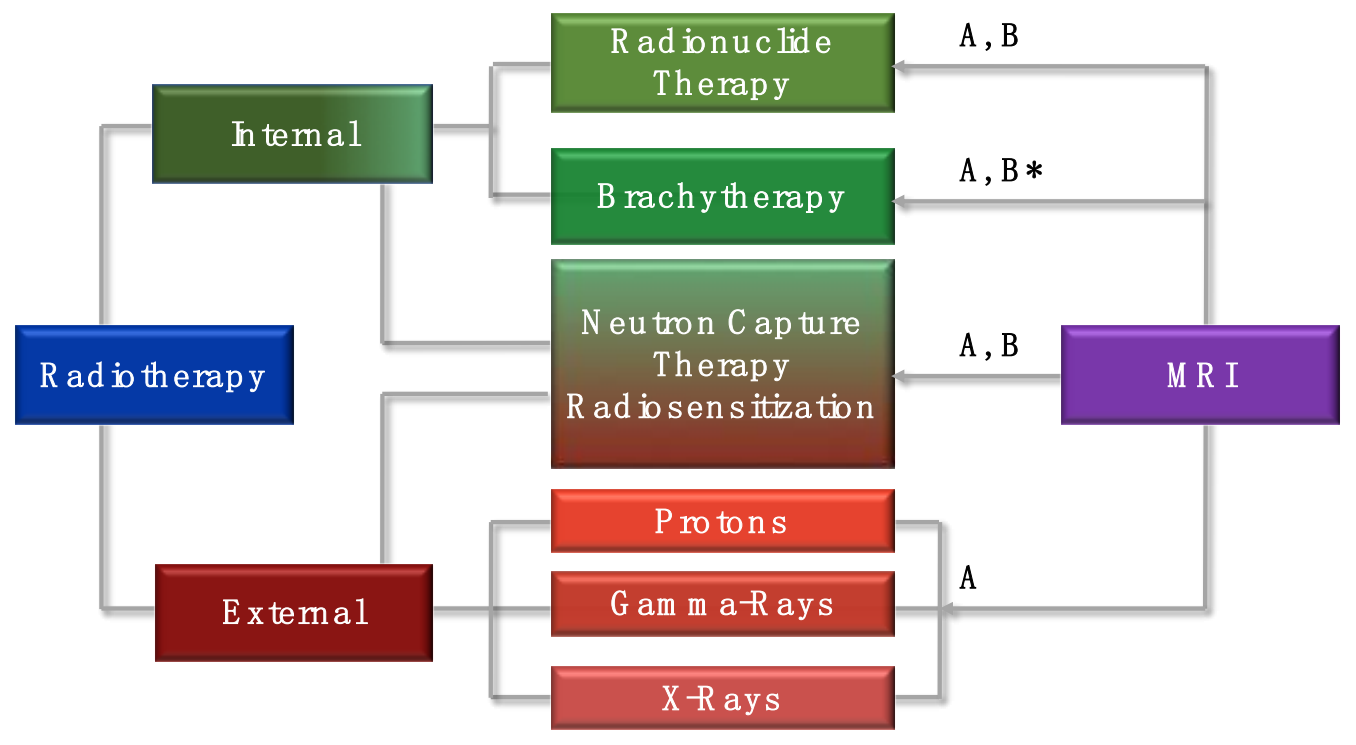

Figure 1. Overview of radiotherapeutic methods and the role of magnetic resonance imaging (MRI) in: (A) treatment planning, including volume of interest delineation and (B) monitoring delivery and distribution of therapeutic agents $(*$ only for non-sealed source brachytherapy). 


\section{The Role of Magnetic Resonance Imaging (MRI) in External Radiation Therapy}

The essence of external radiation therapy (ERT) is the exposure of the patients to ionizing radiation originated from the beams (photons, high-energy electrons, protons or neutrons) produced by linear accelerators, cyclotrons or nuclear reactors. The treatment requires methods to decrease healthy tissues risk, i.e., delivery of the therapeutic dose exclusively to the site of interest. This precision matter involves several strategies, one of which is adjustment of the dose distribution in and around the tumor known as intensity-modulated radiation therapy (IMRT) [7]. In this type of ERT, multiple beams directed to the tumor are modulated in a way to intentionally deliver non-uniform intensity. Other exciting applications are stereotactic radiosurgery (SRS) and stereotactic body radiotherapy (STBT), both of which are types of ERT initially designed to treat small brain tumors with a high precision of 1-2 $\mathrm{mm}$. Thereby, 3D-imaging techniques are used not only to locate and describe the tumor but also to design radiation beams to cover the target area from different angles and plans, which implies careful patient positioning for the RT session. In all the aforementioned techniques, accurate determination of tumor margins and morphology is the key factor, which can typically be achieved with CT. However, in many cases, such as brain or head/neck tumors, the full extent of the tumor can often only be fully visualized by an additional MRI scan on the basis of voxel to voxel matching resulting in a CT-MRI fused image. The study by Emami et al. is, thereby, a good example that shows a significant difference of the tumor volume obtained from the CT images compared to MRI (74\% increase), which consequently leads to underdosing of the applied radiation by $14 \%$ [8].

Another approach to minimize the damage of healthy tissues and enhance the effects of ERT involves the application of radiosensitizers, which are typically therapeutically inert (with exception to chemotherapeutic examples [9]) compounds that increase susceptibility of cells to ionizing radiation and thus improving the dose efficacy [10]. The effect is based on the particular physical properties of radiosensitizers such as high density and high atomic number $(Z)$ of the comprising elements (vide infra). An additional benefit can be gained by providing these agents with the ability to generate an accompanied MRI signal that allows for visualization of the delivery of such theranostic probes to the site of interest as well as monitoring the effects of RT.

\subsection{Radiosensitization}

While careful definition of tumor size, shape and volume can to a certain extent be secured by high-resolution CT or MRI 3D-imaging, increasing the tumor-killing efficiency can be optimized by radiosensitive substances, which either result in additional boost in radiation dose (e.g., Au nanoparticles) or in biologically driven decrease in radiation resistance (e.g., kinase inhibitors). Generally, exposure of a soft tissue to ionizing radiation such as gamma- or X-rays as well as alpha-, beta-particles or electron, proton or neutron beams, causes a cascade of events leading to cell death. In this process, radiation beams, depending on their linear transfer energy, interact with DNA either directly or through the formation of free radicals originating from intracellular water molecules and dissolved oxygen. Metal-based radiosensitizers delivered to the target site are able to create differences between healthy and cancer cells rendering the latter more vulnerable to radiation, which, in turn, affects their proliferation and leads to apoptosis. The principle is based on the high density and high atomic number of the elements composing these agents. In response to irradiation, the electrons of these elements absorb the energy, which is then transformed into kinetic energy sufficient to extract them from the atomic orbitals causing scattering of (fluorescent) photons and photo-, Compton-, or Auger-electrons. The type of effect is mainly determined by the $Z / E$ ratio $(Z=$ atomic number, $E=$ energy of the incoming radiation), where $E$ on its turn defines the range of the effect within the tissue. This phenomenon drew attention for the first time during RT treatment of mandibular cancer patients with high- $Z$ material implants [11] and was demonstrated later for iodine-containing contrast media with radiosensitizing effect on cultured mammalian cells [12]. The most thorough investigation over the last decades, however, was done with high- $Z$ elements, such as gold and mainly in the form of nanoparticles (NPs). 
The general advantage of NPs is their ability to permeate tumor tissues through the leaky vasculature, an effect known as enhanced permeability and retention (EPR), often addressed as passive targeting [13]. The result of such accumulation is slow systemic clearance compared to low-molecular agents, which prolongs the radiosensitizing effect. Additionally, the surface of NPs can be exploited for grafting of various functionalities, for example with polyethylene glycol (PEG) chains that reduce the uptake and removal of NPs by the reticuloendothelial system [14]. Densely packed metal NPs possess higher mass absorption coefficients than those of soft tissues and high scattering cross-sections, which upon irradiation causes release of short-path-length photoelectric and Auger-electrons that induce the localized damage through the formation of free radicals. Gold nanoparticles (AuNPs) represent one of the most important class of radiosensitizing materials demonstrated first by Hainfeld et al. [15]. Applied in EMT-6 mammary carcinoma tumors implanted in mice, AuNPs of $1.9 \mathrm{~nm}$ diameter were delivered intravenously prior to $250 \mathrm{kV}$ X-ray therapy enhancing the outcome. Next to excellent biocompatibility, a valuable additional property of AuNPs is their ability to generate contrast in CT enabling delineation of tumors. However, this review intends to focus on MRI-guided radiotherapy, and therefore, the main accent is on combination of radiosensitizing and magnetic properties of the agents.

\subsubsection{Gadolinium-Based Radiosensitization}

Gadolinium can be considered as the most exciting element envisioned for the combination of MRI with radiosensitization due to its strong paramagnetic nature and high mass-absorption coefficient thanks to its relatively high atomic number $\left(Z_{\mathrm{Gd}}=64\right)$. The paramagnetic properties are due to seven unpaired electrons in the $f$-shell with rather long relaxation times. Coordination numbers of 8-9 and strong complexing properties underlie its wide application as clinical $T_{1}$ MRI CA in the form of small complexes with DOTA- or DTPA-like chelates (DOTA $=1,4,7,10$-tetraazacyclododecane1,4,7,10-tetraacetate; DTPA = diethylenetriamine pentaacetic acid) with high thermodynamic and kinetic stabilities. The parameters governing the efficiency of low-molecular Gd-based MRI CAs are extensively discussed in the literature [16]. Numerous studies over the last two decades have been dedicated to the design of $\mathrm{Gd}(\mathrm{III})$-complexes with modulated number $(q)$ and residence time $\left(\tau_{\mathrm{M}}\right)$ of water molecules in the first coordination sphere and the rotational correlation time $\left(\tau_{\mathrm{R}}\right)$ of the complex in order to increase the $r_{1}$. Recently, an important safety concern has been raised in connection with possible release of toxic "free" Gd(III)-ions in vivo causing nephrogenic systemic fibrosis [17] or their accumulation in the central nervous system [18]. Therefore, every new design of a potential MRI CA molecule towards increased $r_{1}$ by optimization of the aforementioned parameters by chemical modifications requires thorough evaluation of the thermodynamic and kinetic stabilities of the final complex.

A small Gd(III)-complex designed for radiosensitization combined with MRI is porphyrin-like macrocycle motexafin gadolinium (MGd) (Figure 2) that belongs to the texaphyrins class of drugs, which proved effective to mediate radiation of tumors and brain metastasis in particular [19]. A pre-clinical MRI study has revealed a selective uptake of MGd by malignant cells, most probably facilitated by the tumor $\mathrm{pH}$ being lower compared to those of healthy cells. A nine-fold contrast enhancement within $24 \mathrm{~h}$ post-injection (p.i.) into murine mammary tumor mice models was accompanied by the rapid clearance from plasma through the bowel [20]. The therapeutic effect is based on several mechanisms, including depletion of intracellular reducing metabolites, such as ascorbate, glutathione and NADPH that are typically taking part in reparation of oxidative DNA damage upon irradiation. Additionally, MGd was shown to exhibit a synergetic effect in combination with some chemotherapeutics. An example is reduction of platinum (IV) prodrugs to their active form oxaliplatin $(\mathrm{Pt}(\mathrm{II}))$ by the metabolites, such as sodium ascorbate, generated upon photo-irradiation in the presence of MGd accumulated selectively at the tumor [21]. 


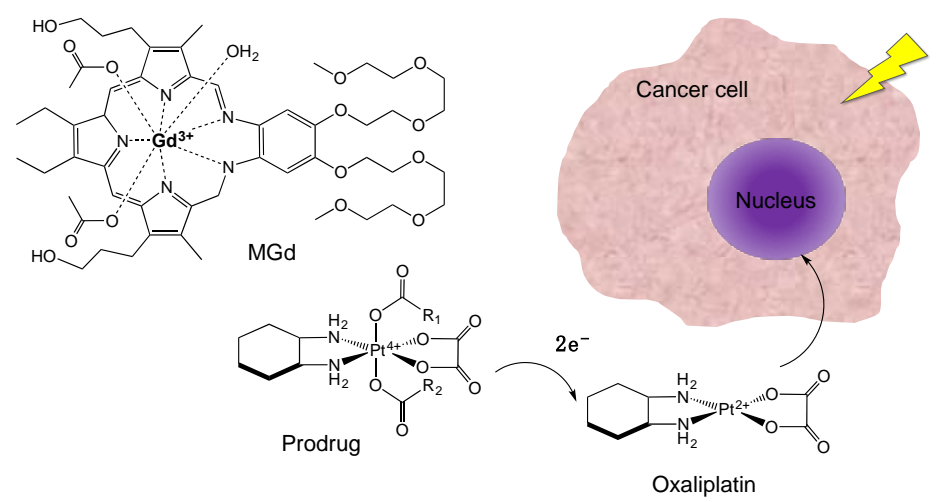

Figure 2. Schematic representation of synergetic effect of motexafin gadolinium (MGd) accumulated at the tumor cells with chemotherapeutics upon photo-irradiation. $\mathrm{Pt}(\mathrm{IV})$ prodrugs vary as: $\mathrm{R}_{1} / \mathrm{R}_{2}=\mathrm{CH}_{3}$, $\mathrm{R}_{1} / \mathrm{R}_{2}=\mathrm{CH}_{2} \mathrm{CH}_{3}, \mathrm{R}_{1} / \mathrm{R}_{2}=\left(\mathrm{CH}_{2}\right)_{2} \mathrm{COOH}$, or $\mathrm{R}_{1}=\left(\mathrm{CH}_{2}\right)_{2} \mathrm{COOH}, \mathrm{R}_{2}=\mathrm{CH}_{3}$ [21].

In general, the strategies to enhance the MRI performance of $T_{1}$ CAs include either accommodation of multiple $\mathrm{Gd}(\mathrm{III})$-complexes on nanocarriers or application of Gd-containing NPs; both concepts striving for a higher payload of paramagnetic units increasing the $r_{1}$ per $\mathrm{Gd}(\mathrm{III})$-ion [22]. Development of a polyol method for the synthesis of crystalline core $\mathrm{Gd}_{2} \mathrm{O}_{3}$ NPs [23] within the size-range of 1-5 nm enabled a series of studies that demonstrated higher $r_{1}\left(8.8 \mathrm{~s}^{-1} \cdot \mathrm{mM}^{-1} \mathrm{vs} .4 .1 \mathrm{~s}^{-1} \cdot \mathrm{mM}^{-1}\right.$ of Gd(III)-DOTA) based on the additional contribution of Gd-ions located inside the core [24]. In terms of radiosensitization, densely packed NPs show an increased ability to scatter/absorb the X-rays and gamma radiation that leads to more localized damage of targeted cancer cells. Lux and co-workers have developed an original top-down process for the preparation of ultrasmall Gd-NPs with a size below $5 \mathrm{~nm}$, convenient for in vivo circulation and renal clearance $[25,26]$. The method consisted of several steps, starting with the initial preparation of $\mathrm{Gd}_{2} \mathrm{O}_{3}$ core, which was then encapsulated into a polysiloxane shell that was conjugated with DOTAGA (1,4,7,10-tetra-azacyclododecane-1-glutaric anhydride-1,4,7,10-triacetic acid) ligands. The subsequent dissolution of the core has led to chelation of the released $\mathrm{Gd}(\mathrm{III})$-ions by the ligands and defragmentation of the shell yielding ultrasmall NPs (Figure $3 \mathrm{~A})$. The stability of the resulting complexes $\left(\log \beta_{110}=24.8\right)$, was found to be very close to that of DOTA $\left(\log \beta_{110}=25.6\right)$, while the $r_{1}$ measured at $60 \mathrm{MHz}$ was $11.9 \mathrm{~s}^{-1} \cdot \mathrm{mM}^{-1}$ per Gd(III). The intravenous injection of these NPs into gliosarcoma-bearing rats resulted in a swift accumulation ( $10 \mathrm{~min}$ ) in the tumor through the EPR effect. The MRI data was used to determine the timepoints for the subsequent application of microbeam radiation therapy (MRT). Accumulated at the tumor, Gd-NPs acted as radiosensitizers upon irradiation and the therapeutic effect was demonstrated by the different median survival of the MRT-treated animals with (48 days) and without (20 days) administration of NPs (Figure 3B-D). An additional application of these NPs was demonstrated by intratracheal administration for MRI visualization of lung cancer, which was possible due to their small size $(\sim 3 \mathrm{~nm})$ and hence the ability to pass through the pulmonary airways and be excreted later through the kidneys [27].

Further progress with these NPs has been made by incorporation of bismuth $\mathrm{Bi}(\mathrm{III})$ into DOTA-chelates on the surface of the aforementioned silica carrier with $\mathrm{Gd} / \mathrm{Bi}$ ratio of 8/6 [28]. The presence of bismuth resulted in strengthening of radiosensitizing effect due to its high atomic number $\left(Z_{\mathrm{Bi}}=83\right)$ and additional possibility to visualize the particles by $\mathrm{CT}$. MRI monitoring of the arrival of the particles after intravenous injection into lung carcinoma-bearing mice was used to determine the right timing ( $30 \mathrm{~min}$ p.i.) for the delivery of $10 \mathrm{~Gy}$ radiation dose. Evaluation of double-strand DNA breaks for both tumor and healthy tissues was used as quantification of radiosensitizing effect, which eventually resulted in significantly higher survival rate for the animals irradiated after injection of Gd/Bi NPs. 


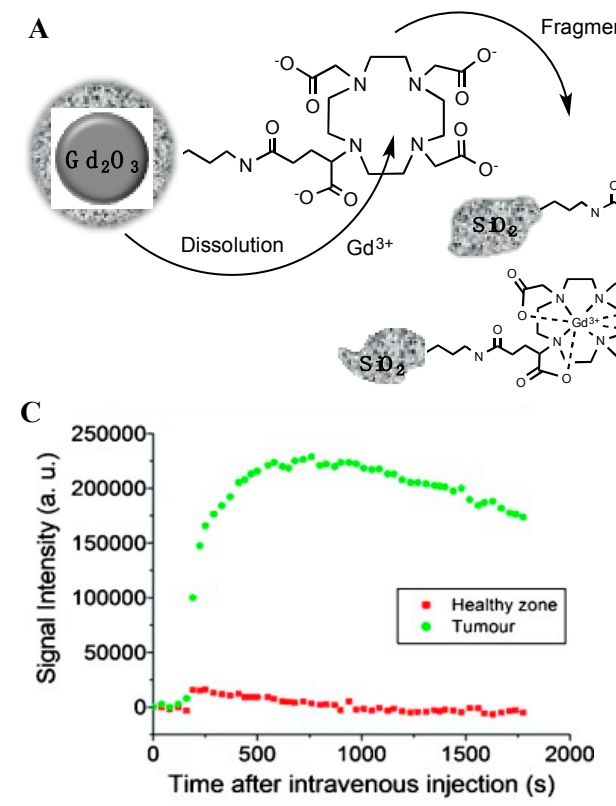

B
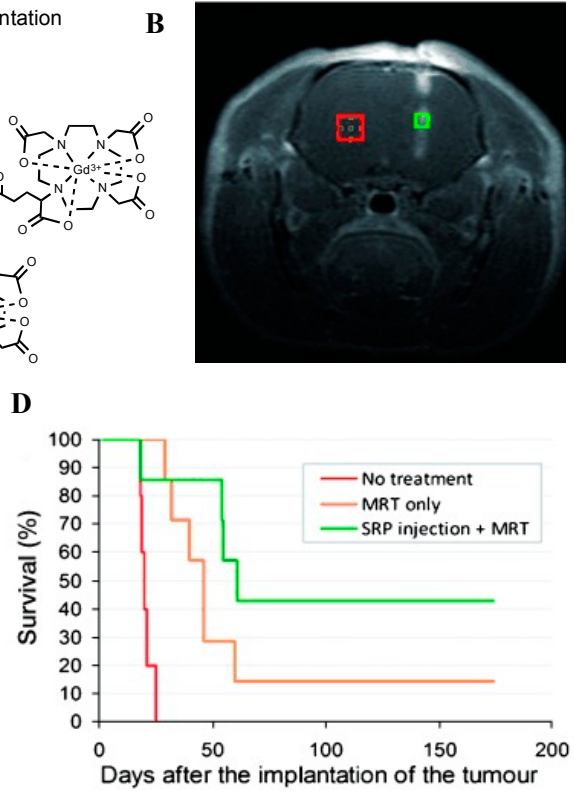

Figure 3. MRI/microbeam radiation therapy (MRT) study with Gd nanoparticles (NPs): (A) top-down process going from $\mathrm{Gd}_{2} \mathrm{O}_{3}$ coated with $\mathrm{SiO}_{2}$ conjugated with DOTAGA $(1,4,7,10$-tetraazacyclododecane-1-glutaric anhydride-1,4,7,10-triacetic acid), followed by dissolution and complexation of Gd(III)-ions and fragmentation of ultrasmall NPs; (B) $T_{1}$-weighted MR image of rat's brain overexpressing gliosacroma tumor. Green and red area indicate tumoral and non-tumoral accumulation of NPs, respectively; (C) MRI signal obtained at 7T following accumulation of NPs in tumor and healthy zone over time; (D) animal survival rate without treatment and after application of dose rate of $90 \mathrm{~Gy} \cdot \mathrm{s}^{-1} \cdot \mathrm{mA}^{-1}$ with and without administration of NPs. Reprinted with permission from ref. [25].

Carbon quantum dots (CDs) represent another interesting nanoplatform for MRI-guided radiosensitization. Doping of carbon crystals with Gd could be achieved through hydrothermal carbonization of Gd-DTPA in the presence of glycine as passivation agent resulting in a composite, resistant for Gd-leakage even under harsh conditions [29]. The $r_{1}$ relaxivity of $6.5 \mathrm{~s}^{-1} \cdot \mathrm{mM}^{-1}$, which was higher than that of Gd-DTPA $\left(4.5 \mathrm{~s}^{-1} \cdot \mathrm{mM}^{-1}\right)$, was attributed to the much larger hydrodynamic surface area of CDs ( 20 nm) with Gd-ions in the lattice. The intravenous injection of Gd-CDs into a tumor-bearing mouse was followed by MRI, starting with passive accumulation and retention in the tumor and ending with the final renal clearance of the probe. The remarkable radiosensitizing efficacy was demonstrated in a single treatment of HepG2 cells by 8 Gy X-ray radiation leading to reduced growth by $90.1 \%$ and further shrinkage of the tumor by $53 \%$ in 7 days, compared to $12 \%$ for the group of mice irradiated in the absence of Gd-CDs.

\subsubsection{Iron Oxide Nanoparticles}

The use of superparamagnetic iron oxide nanoparticles (SPIONs, mainly magnetite $\left(\mathrm{Fe}_{3} \mathrm{O}_{4}\right.$ ) or maghemite $\left.\left(\gamma \mathrm{Fe}_{2} \mathrm{O}_{3}\right)\right)$ in medical field ranges from various types of therapies, such as targeted drug delivery, immunoassays, hyperthermia and tissue repair to diagnosis by MRI [30]. The latter application relies on the ability of SPIONs to generate dark contrast promoted by magnetic domains within iron oxide crystals containing unpaired electrons. Gathered in one particle, the single-domains display a strong collective magnetic moment that results in magnetic susceptibility, disruption of external magnetic field homogeneity, and creation of field gradients. Consequently, the transversal relaxivity of water molecules diffusing in the vicinity of SPIONs is reduced significantly, leading to a $T_{2}$-weighted contrast, while the emerged field inhomogeneities induce a $T_{2}{ }^{*}$-weighted contrast [31]. Intracellular delivery of SPIONs is to a great extent determined by the size of the particles as well 
as functionalization of their surface with various coatings and conjugated vectors for increased affinity towards certain pathological epitopes. These features of SPIONs along with the available facile manufacturing methods have led to many interesting formulations for labeling and in vivo MRI-tracking of stem cells, imaging of apoptosis and inflammation [32]. In general, the small size of the particles allows them to penetrate small capillaries and be captured and retained by the affected cells. Using SPIONs as drug delivery systems carrying conjugated chemotherapeutics, such as e.g., methortrexate that can be cleaved from the surface under intracellular conditions, represents an interesting strategy, especially when the process can be monitored by MRI [33]. Medarova et al. have demonstrated a possibility to track tumor response for chemotherapy by application of SPION's decorated with peptides for recognition of mucin-1 tumor-specific antigen (uMUC-1) attached to their crosslinked dextran coating. MR images acquired on mice with pancreatic adenocarcinomas clearly indicated alteration of $T_{2}$-weighted contrast before and after the treatment with the chemotherapeutic agent 5-FU [34].

The multifunctional potential of SPIONs is currently being extended to radiosensitization applications (Table 1), despite the less convenient characteristics of iron $\left(Z_{\mathrm{Fe}}=56, \mathrm{X}\right.$-ray absorption enhancement factor $(\mathrm{AEF})=1.2)$ compared to gold $\left(Z_{\mathrm{Au}}=79, \mathrm{AEF}=1.6\right)$. Radiosensitization typically occurs due to interaction between high $Z$ materials and low energy $X$-rays (kV-range) through photoelectric effects, while at higher energies Compton effects are dominating. Therefore, the shift to the megavoltage range can be seen as beneficial for clinical applications due to skin sparing and convenient dose-distribution to the deep-seeded tumors, such as in case of colon cancer [35]. Recent studies revealed that the radiosensitizing effect of dextran-crosslinked SPIONs exposed to $6 \mathrm{MV}$ X-rays might be both concentration and dose-rate dependent with the optima observed at $80 \mu \mathrm{g} / \mathrm{mL}$ and $370 \mathrm{cGy} / \mathrm{min}$, respectively [36]. Another study by Khoei et al. with human prostate carcinoma DU145 cell line demonstrated that coating of particles with dextran with additional amino-groups increases the cellular uptake significantly compared to plain particles (only dextran-coating). As the result, the best MRI enhancement by $\mathrm{NH}_{2}$-dextrane-SPIONs was observed for the concentration of $1 \mathrm{mg} / \mathrm{mL}$ and the radiosensitization effect was found to be dose-independent under MV energies [37].

Table 1. Examples of superparamagnetic iron oxide nanoparticles (SPIONs) applied as radiosensitizing MRI contrast agents.

\begin{tabular}{|c|c|c|c|c|c|c|}
\hline Composition/Coating & $\begin{array}{l}\text { Preparation } \\
\text { Method }\end{array}$ & $\begin{array}{l}\text { Size } \\
(\mathrm{nm})\end{array}$ & $\begin{array}{l}\text { Radiation } \\
\text { Energy }\end{array}$ & Cell Line & $\begin{array}{c}\text { Tested } \\
\text { Application }\end{array}$ & Ref. \\
\hline $\mathrm{Fe}_{3} \mathrm{O}_{4} /$ dextran & Co-precipitation & 15 & $6 \mathrm{MV}$ & MCF-7/HeLa & ERT & [36] \\
\hline SPIONs/dextran- $\mathrm{NH}_{2}$ & -1 & 130 & $6 \mathrm{MV}$ & DU 145 & ERT/MRI & [37] \\
\hline$\gamma \mathrm{Fe}_{2} \mathrm{O}_{3} / \mathrm{Fe}_{3} \mathrm{O}_{4} /$ citrate & Co-precipitation ${ }^{3}$ & $\begin{array}{l}6-20^{2} \\
3-10^{3}\end{array}$ & $120 \mathrm{kV}$ & MCF-7 & ERT & [38] \\
\hline SPIONs/citrate & Co-precipitation & $6-25$ & $6 \mathrm{MV}$ & $\begin{array}{c}\text { MCF-7/MDAH- } \\
\text { 2447/MDA-MB-231 }\end{array}$ & ERT & [39] \\
\hline $\mathrm{BiFeO}_{3}$ & Sol-gel & 30 & $160 \mathrm{kV}$ & MCF-7 & MRI/ERT/CT/HT & [40] \\
\hline $\mathrm{Fe}_{3} \mathrm{O}_{4} / \mathrm{Ag} / \mathrm{C} 225$ & Co-precipitation & 102 & $6 \mathrm{MV}$ & $\mathrm{CNE}$ & ERT & [41] \\
\hline $\begin{array}{c}\mathrm{Fe}_{4}\left[\mathrm{Fe}(\mathrm{CN})_{6}\right]_{3}-\mathrm{Au} / \\
\text { citrate-PEG }\end{array}$ & $\begin{array}{l}\text { Electrostatic } \\
\text { absorption }\end{array}$ & 139 & - & $4 \mathrm{~T} 1$ & MRI/CT/PTT/ERT & [42] \\
\hline
\end{tabular}

${ }^{1}$ Commercially available; ${ }^{2} 0{ }^{\circ} \mathrm{C} ;{ }^{3} 220{ }^{\circ} \mathrm{C}$.

The necessity of an appropriate coating of the metal core, which applies for any NPs envisioned for in vivo applications, becomes particularly interesting in case of SPIONs. Next to decreased toxicity by ion-leakage inhibition, the arguments for coating are surface passivation, prevention of aggregation and interaction with reticuloendothelial system. All these measures ultimately lead to prolonged blood-circulation time and increase the chance for accumulation at the site of interest. The choice of coating materials, in addition to influences on the aforementioned parameters, has a dramatic effect on the MRI performance of SPIONs. For instance, coating of the core of the SPIONs with carboxylates leads to a drop of net magnetization and the consequent decrease of the $T_{2}$-effect, which is not observed in case of phosphate coating [43]. On the other hand, the presence of hydrophilic molecules promotes a 
greater hydration around the particles and results in higher relaxivity of surrounding protons. The role of the chain length of coating polymers on the $r_{2}$ relaxivity is determined by the access of water molecules to the metal core. Generally, long PEG-chains tend to reduce relaxivities due to prohibition of diffusing water molecules from contact with the magnetic core. However, when PEG is anchored to SPIONs in a single layer, water molecules are not excluded from such interactions and high relaxivities can be achieved even with smaller particles based on slow diffusion and hence more efficient dephasing of magnetic moments [44].

Interesting results have been obtained by Klein et al. who have studied the effects of coating density on the radiosensitization properties of SPION's [38]. The intrinsic toxicity of SPIONs is based on generation of oxygen reactive species (ROS), such as $\mathrm{H}_{2} \mathrm{O}_{2}, \mathrm{OH}, \mathrm{HO}_{2}{ }^{\circ}$, and $\mathrm{O}_{2}{ }^{-}$that are produced upon release of iron ions from particles endocytosed into tumor cells. Application of SPIONs that are partially coated with citrate induced cooperative toxicity under X-ray irradiation, resulting in enhancement of radiosensitizing effect due to increase of ROS formation by $240 \%$. Thereby, the effect was found to be more pronounced in case of SPIONs containing both maghemite and magnetite domains (high-temperature preparation) compared to SPIONs containing maghemite only (low-temperature preparation). In vitro studies on three types of human carcinoma cell lines (ovarian, breast estrogen receptor positive and negative) incubated with the same amount of citrate coated SPIONs and exposed to $6 \mathrm{MV}$ X-rays showed that the best AEF could be achieved at 2 and 4 Gy for the first two and the latter cell line, respectively [39]. Moreover, no further radiosensitization effect enhancement was found above $8 \mathrm{~Gy}$, which means that irradiation can be done at low doses adopted for specific tumor cells.

Combination of iron with other metals was also explored for theranostic purposes. Rajaee et al. considered $\mathrm{Bi}$ as a more efficient radiosensitizer due to its higher atomic number $\left(Z_{\mathrm{Bi}}=82\right)$, while keeping the benefits of combination of high photoelectric absorption and magnetic properties of iron [40]. Bismuth ferrite nanoparticles $\left(\mathrm{BiFeO}_{3}\right)$ of the size $\sim 30 \mathrm{~nm}$, prepared by the sol-gel method using equal amounts of $\mathrm{Bi}$ and $\mathrm{Fe}$, displayed excellent MRI properties in addition to CT contrast due to the high density of $\mathrm{Bi}$. Furthermore, the $\mathrm{BiFeP}_{3}$ particles showed response to inductive heating at $480 \mathrm{kHz}$ enabling their applicability as magnetic hyperthermia (HT) mediators, which is considered advantageous for improved efficacy of radiotherapy [45]. Another group investigated synergetic MRI/ERT performance of SPIONs combined with silver $\left(Z_{\mathrm{Ag}}=47\right)$ in a single particle [41]. In this study, $\mathrm{Fe}-\mathrm{Ag}$ NPs were conjugated to an epidermal growth factor (EGFR) receptor-specific monoclonal antibody (C225) currently applied in the clinic for the treatment of advanced brain tumors. The researchers demonstrated $80 \%$ inhibition of proliferation of carcinoma cells (CNE) in the presence of $8 \mathrm{mg} / \mathrm{L}$ of nanocomposite and down-regulation of EGFR, but most importantly, the accompanying enhancement of sensitivity of CNE to X-ray irradiation by 2.3-fold. Dou et al. have doped clinically applied cubic shaped (83 nm) Prussian Blue NPs with AuNPs (13 nm) via electrostatic adsorption [42]. After PEGylation, the final nanocomposite $(138 \mathrm{~nm})$ injected intravenously into $4 \mathrm{~T} 1$ xenograft bearing mice was observed by MRI (both $T_{1}$ - and $T_{2}$-weighted images) and CT (gold-contrast) showing accumulation at the tumor site after $24 \mathrm{~h}$ p.i. Further exposure of the tumor-bearing animals to both photothermal therapy (PTT) by near-infrared (NIR) treatment (heating of tissues up to $55^{\circ} \mathrm{C}$ in the presence of iron) and X-ray irradiation showed reduction of tumor volumes by $\sim 94 \%$, compared to $39 \%$ and $47 \%$ of each individual therapy, respectively. The results were correlated with the ability of RT to reach deeply located cancer cells, while PTT increases the sensitivity of the radio-resistant hypoxic cells to X-ray irradiation.

\section{The Role of MRI in Internal Radionuclide Therapy}

Internal radionuclide therapy (IRT) is gaining increased attention as a type of cancer treatment shown to increase life expectancy for terminal patients up to several years with a good quality of life [46]. Regarding the application of radiation emitting nuclides, the main advantage of IRT is the delivery of a highly concentrated radiation dose to metastasized malignancies otherwise untreatable by 
external radiation beams, such as bone metastases. Radiolabeled molecules used for this treatment are often referred to as radiotherapeutics or radiopharmaceuticals. Physical properties of the constituting radionuclides, e.g., half-life, type of emission, energy, possible daughter nuclides, and production routes, are the first determinants in the radionuclide choice for every particular therapy or palliation treatment [47]. However, the biochemical characteristics of radiopharmaceuticals, such as their biological half-life and tumor uptake, retention, and clearance mechanisms also play an important role. The ability of selective delivery of radiotherapeutics to the tumors as well as fast clearance is decisive for their safety as well as the final therapeutic outcome. To achieve this, the current strategies include exploitation of metabolic pathways (e.g., accumulation of ${ }^{131} \mathrm{I}$ in thyroid cancer [48]), targeting overexpressed receptors or antigens by radiolabeled peptides or monoclonal antibodies [49], and natural uptake of bone-seeking radiopharmaceuticals [50]. The most important examples of therapeutic radionuclides and their physical properties are listed in Table 2. More detailed description can be found elsewhere [51]; here we focus on specific examples of MRI contrast agents designed for combination with IRT.

A special type of IRT is represented by interstitial brachytherapy in which a radiation source is sealed in a small seed $(\mathrm{mm})$ that is placed directly into a tumor (typically prostate) under anesthesia. Depending on the intended dose, the treatment can vary from a few minutes (high-dose rate) to a few days (low-dose rate). In some cases, the seeds can even be left in place permanently. MRI certainly plays an important role prior to the treatment planning [52], but there are currently no examples of sealed radiation sources with additional MR imaging properties. The potential of MRI in combination with internal radiotherapy is most evident in studies applying ${ }^{166} \mathrm{Ho}$-containing microspheres [53]. These radioactive microspheres are used primarily for liver radioembolization, but their application can be extended to intratumoral treatments as a promising new brachytherapy method. The polymeric microspheres contain ${ }^{165} \mathrm{Ho}$, part of which is converted to ${ }^{166} \mathrm{Ho}$ upon neutron activation. The ${ }^{166} \mathrm{Ho}$ with its convenient half-life of $26.8 \mathrm{~h}$, has a maximum $\beta$-energy of $1.9 \mathrm{MeV}$, applicable to kill tumors, as well as a gamma emission of $81 \mathrm{keV}$, suitable for single photon emission computed tomography (SPECT) imaging. Furthermore, the magnetic moment of ${ }^{165}$ Ho being one of the highest among the whole series of lanthanides $(10.6 \mu \mathrm{B})$, this enables simultaneous monitoring of the therapeutic events by $T_{2}$-weighted MRI [54]. In the clinical study by Smith et al. a total of 15 patients excluding those having surgical clips (to avoid interferences in the MRI evaluations) were evaluated [55]. The SPECT and MRI data obtained showed high correlation, which however raised some questions in terms of dosimetry. The high resolution of MRI is undoubtfully superior for collection of dosimetric data in small areas, but when the microspheres are located near the organs containing air, such as lungs, the susceptibility artefacts of MRI lead to decreased accuracy of the method. The authors concluded that although a direct comparison between SPECT and MRI is difficult, the two techniques are complementary to each other and MRI had the advantage of providing biodistribution long after the activity of ${ }^{166} \mathrm{Ho}$ had decayed allowing for better post-treatment evaluation (Figure 4). The added value of MRI was also evaluated in intratumoral injections of the ${ }^{166} \mathrm{Ho}$ microspheres in lab animals having orthotopic renal tumors. The results showed that combination of the high sensitivity of SPECT and the high-resolution soft-tissue contrast of MRI was beneficial in assessment of the distribution of the microspheres within the tumor to ascertain proper tumor coverage.

Another potential for MR-assisted IRT lies in the application of SPIONs radiolabeled with therapeutic radionuclides. The first example is radiolabeling of NPs with ${ }^{188} \mathrm{Re}$ (half-life of $17 \mathrm{~h}$ and maximum $\beta$-energy of $2.1 \mathrm{MeV}$ ), which is one of the radionuclides used routinely in the clinic. Production through ${ }^{188} \mathrm{~W} /{ }^{188}$ Re-generator, convenient in clinical environment, has already stimulated development of several ${ }^{188}$ Re-radiolabeled biomolecules. Several SPIONs platforms coated with silica [56], human serum albumin [57], polyacrylamide [58] or prepared within apoferritin cavities [59] have been explored for the application in magnetically targeted radiotherapy. The rationale behind this approach is to profit from the localized magnetic field gradients to attract the NPs to the tumor for the subsequent radiotherapy. The radiolabeling yield and in vitro stability of the NPs prepared in the 
aforementioned studies are high, and even though the MRI performance of these materials has not been investigated in particular, its potential certainly exists and can be explored for radiotheranostic purposes.
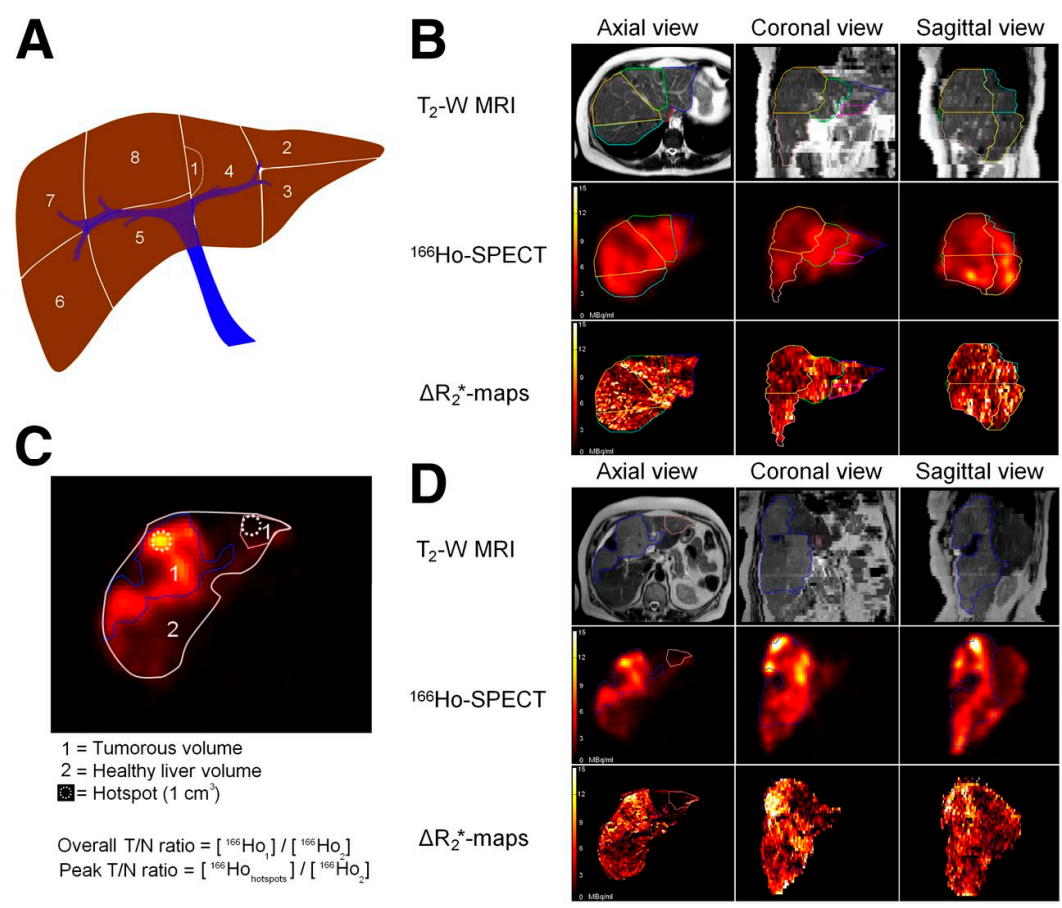

Figure 4. Single photon emission computed tomography/magnetic resonance (SPECT/MR) imaging of ${ }^{166}$ Ho-microspheres for treatment of liver cancer: (A) schematic overview of liver segments; (B) delineation of liver segments on $T_{2}$-weighted MR images (top row), volumes of interest (VOIs) registered to SPECT activity maps (middle row), $\Delta R_{2}{ }^{*}$-based activity maps for some set of VOIs; (C) schematic overview of created tumor VOIs and calculations of tumor-to-nontumor ratios and the fine distribution assessment; (D) delineation of tumors. Reprinted with permission from ref. [54].

Table 2. Most important radionuclides for internal radionuclide therapy (IRT).

\begin{tabular}{cccccc}
\hline $\begin{array}{c}\text { Radio- } \\
\text { Nuclide }\end{array}$ & $\begin{array}{c}\text { Half- } \\
\text { Life }\end{array}$ & $\begin{array}{c}\text { Decay } \\
\text { Mode }\end{array}$ & $\begin{array}{c}\text { Soft Tissue } \\
\text { Range }(\mathbf{m m})\end{array}$ & Product & Most Common Clinical Application ${ }^{\mathbf{1}}$ \\
\hline${ }^{166} \mathrm{Ho}$ & $26.8 \mathrm{~h}$ & $\beta^{-}$ & 8.5 & ${ }^{166} \mathrm{Er}$ & Hepatic cancer [54] \\
${ }^{186} \mathrm{Re}$ & $3.7 \mathrm{~d}$ & $\beta^{-} / \varepsilon$ & 3.6 & ${ }^{186} \mathrm{Os} / 186 \mathrm{~W}$ & Bone metastasis, arthritis \\
${ }^{188} \mathrm{Re}$ & $17.0 \mathrm{~h}$ & $\beta^{-}$ & 11.0 & ${ }^{188} \mathrm{Os}$ & Bone metastasis, arthritis [59] \\
${ }^{89} \mathrm{Sr}$ & $50.6 \mathrm{~d}$ & $\beta^{-}$ & 8.0 & ${ }^{89} \mathrm{Y}$ & Bone metastasis \\
${ }^{177} \mathrm{Lu}$ & $6.7 \mathrm{~d}$ & $\beta^{-}$ & 1.7 & ${ }^{177} \mathrm{Hf}$ & Various cancers \\
${ }^{90} \mathrm{Y}$ & $64.6 \mathrm{~h}$ & $\beta^{-}$ & 11.0 & ${ }^{90} \mathrm{Zr}$ & Hepatic metastasis [60] \\
${ }^{153} \mathrm{Sm}$ & $46.3 \mathrm{~h}$ & $\beta^{-}$ & 3.4 & ${ }^{153} \mathrm{Eu}$ & Bone metastasis \\
${ }^{165} \mathrm{Dy}$ & $2.3 \mathrm{~h}$ & $\beta^{-}$ & 5.7 & ${ }^{165} \mathrm{Ho}$ & Rheumatoid arthritis \\
${ }^{32} \mathrm{P}$ & $14.3 \mathrm{~d}$ & $\beta^{-}$ & 7.9 & ${ }^{32} \mathrm{~S}$ & Cystic craniopharyngioma \\
${ }^{223} \mathrm{Ra}$ & $11.4 \mathrm{~d}$ & $\alpha$ & 0.01 & ${ }^{219} \mathrm{Rn}$ & Bone metastasis \\
${ }^{131} \mathrm{I}$ & $8.0 \mathrm{~d}$ & $\beta^{-}$ & 2.4 & ${ }^{131} \mathrm{Xe}$ & Thyroid cancer, neuroblastoma [61,62] \\
${ }^{125} \mathrm{I}$ & $59.4 \mathrm{~d}$ & $\gamma / \varepsilon$ & 17.0 & ${ }^{125} \mathrm{Te}$ & Brachytherapy of prostate cancer, postsurgical \\
& & & & & treatment of brain cancer, uveal melanoma [62] \\
\hline
\end{tabular}

${ }^{1}$ The references are given for the existing studies demonstrating potential for combination IRT with MRI.

In the next example, the magnetite SPIONs were radiolabeled with ${ }^{90} \mathrm{Y}$ [60], which is a high energy $\beta$-emitter $(2.27 \mathrm{MeV})$ with a half-life of $64.1 \mathrm{~h}$, known to affect the tumors at a maximum depth up to $10-11 \mathrm{~mm}$ due to the ability of $\beta$-radiation to cross multiple individual cells. Targeting of tumor cells with this radionuclide is, therefore, not strictly necessary, provided that accurate accumulation of the particles in tumors can be performed and monitored by MRI. In this study, ${ }^{90} \mathrm{Y}$ labeling was successfully achieved with either naked- or $\mathrm{PEG}_{600}$-coated $\mathrm{Fe}_{3} \mathrm{O}_{4}$-NPs. In the case of naked NPs, the surface $\left(\equiv \mathrm{FeOH}_{2}{ }^{-}\right)$was deprotonated at $\mathrm{pH}>6.2\left(\equiv \mathrm{FeO}^{-}\right)$to enable stable electrostatic interaction with 
${ }^{90} \mathrm{Y}(\mathrm{III})$-ion, yielding $97 \%$ radiolabeling. Radiolabeling of PEGylated NPs was possible due to their carboxylate-reach surface interacting with positively charged tracer leading to $99 \%$ yield. Both types of particles exhibited superparamagnetic behavior at room temperature, which was considered suitable for in vivo hyperthermia under clinical magnetic field frequency of $580 \mathrm{kHz}$. The biodistribution studies in healthy Wistar rats showed a substantial accumulation of NPs in liver and lungs. The latter uptake was particularly high in case of non-PEGylated ${ }^{90} \mathrm{Y}^{-}-\mathrm{Fe}_{3} \mathrm{O}_{4} \mathrm{NPs}$ due to in vivo agglomeration, while PEGylated analogues exhibited longer blood-circulation time, and were therefore, considered suitable for $\beta$-therapy of liver malignances with additional visualization by MRI.

Labeling of MRI contrast agents with various radioisotopes of iodine offers advantages for multimodal imaging (SPECT $\left({ }^{123} \mathrm{I}\right)$, positron emission tomography PET $\left({ }^{124} \mathrm{I}\right)$ ), as well as biological research $\left({ }^{125} \mathrm{I}\right)$ and radiotherapy $\left({ }^{131} \mathrm{I}\right)$. Chen et al. came up with an integrative approach for gene therapy combined with IRT using commercial SPIONs (SilenceMag) designed for in vivo gene delivery and targeted cell transfection with nucleic acids, as nanocarriers and imaging reporters [61]. The positively charged surface of these NPs interacts with negatively charged phosphate backbone of RNAs that can be then delivered to the target under application of external magnetic field (EMF). In this study, the authors aimed at targeting of hepatocellular carcinoma (HCC) cells known to overexpress vascular endothelial growth factor (VEGF) that correlates with progressive tumor growth. Prior to conjugation, the human VEGF siRNA was first modified chemically in order to (i) increase its biological half-life time and (ii) provide the molecule with a linker for the subsequent radiolabeling with ${ }^{131}$ I-containing Bolton Hunter reagent (Figure 5A). Then the ${ }^{131}$ I-hVEGF siRNA/SilenceMag NPs were injected into HCC bearing mice xenograft and prolonged blood-circulation in the presence of EMF (2.22 vs. $3.37 \mathrm{~h}$ ) with a significant accumulation at the tumor site was demonstrated (Figure 5B).
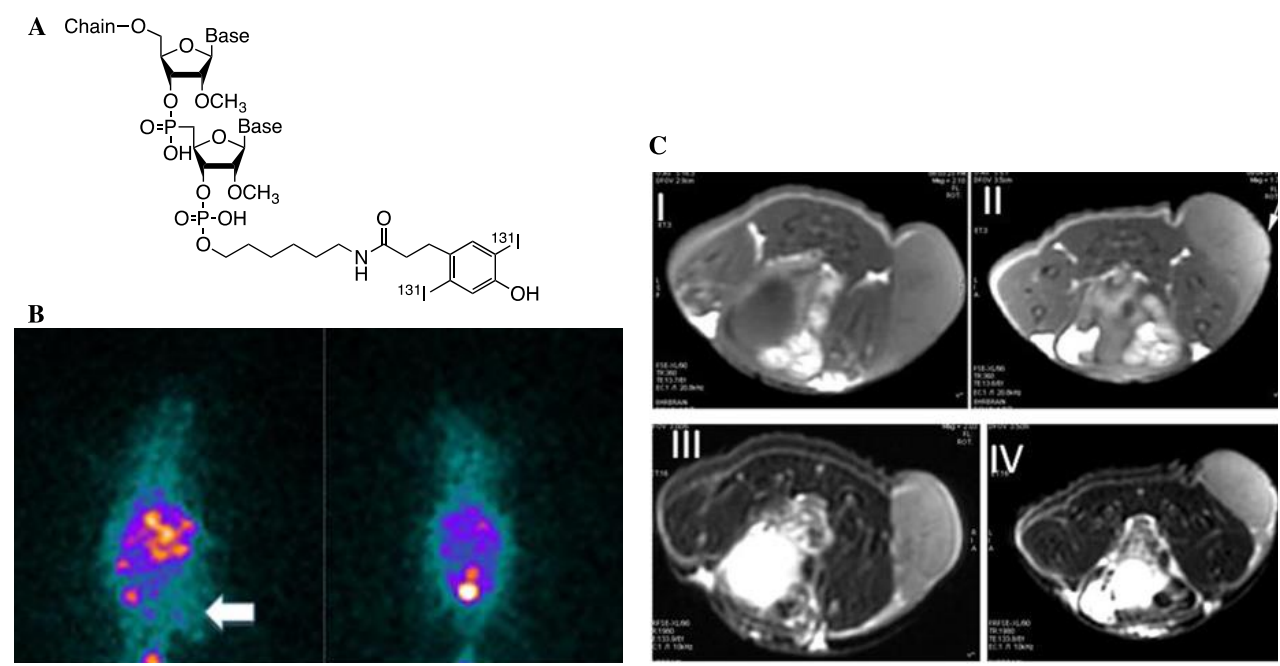

Figure 5. (A) Structure of modified ${ }^{131}$ I-labeled hVEGF (vascular endothelial growth factor) siRNA used for conjugation with SilenceMag; Visualization of the probe $30 \mathrm{~min}$ p.i. into HepGr hepatocellular carcinoma (HCC)-bearing mice xenograft by (B) scintigraphy and (C) MRI in the presence (left) and absence (right) of external magnetic field (EMF), applying $T_{1}$ - (I and II) and $T_{2}$-weighting (II and IV). Reprinted with permission from ref. [61].

Examination of the therapeutic effect of ${ }^{131}$ I-hVEGF siRNA/SilenceMag revealed decreased final tumor weight with the inhibition rate of $49.8 \%$ and a dramatic decrease of VEGF protein expression.

Localization of ${ }^{131}$ I-hVEGF siRNA/SilenceMag using MR could be done by $T_{1}$-weighted imaging visualizing the periphery of tumors, while $T_{2}$-weighted imaging was surprisingly less effective (Figure 5C). This phenomenon was attributed to either a small amount of SilenceMag entering the tumor microenvironment or the inefficiency of SPIONs to create local field inhomogeneity and dephase magnetic moments of protons leading to $T_{2}$-shortening. However, the therapeutic efficiency of 
the probe due to the radiosensitizing effect allows for the assumption that application of the same radiolabeling strategy to SPIONs with physical properties optimized for MRI will enable synergetic radiotheranostic treatment of HCC.

An elegant approach for combination of MRI with IRT was proposed in a recent study [62] reporting one-pot synthesis of a dendrimer-like star polymer conjugated with Gd(III)-DOTA and radiolabeled with ${ }^{125} \mathrm{I}$ (Figure 6). The presence of multiple paramagnetic chelates (25/molecule) and slow molecular dynamics endowed the NPs with high $r_{1}$ relaxivity promising for MR imaging. At the same time, efficient radiochemical yield (58\%) enables the application of this probe for combined PET imaging, opening at the same time the possibilities for therapy either in the current form or by substitution of the radiolabel with ${ }^{131} \mathrm{I}$.

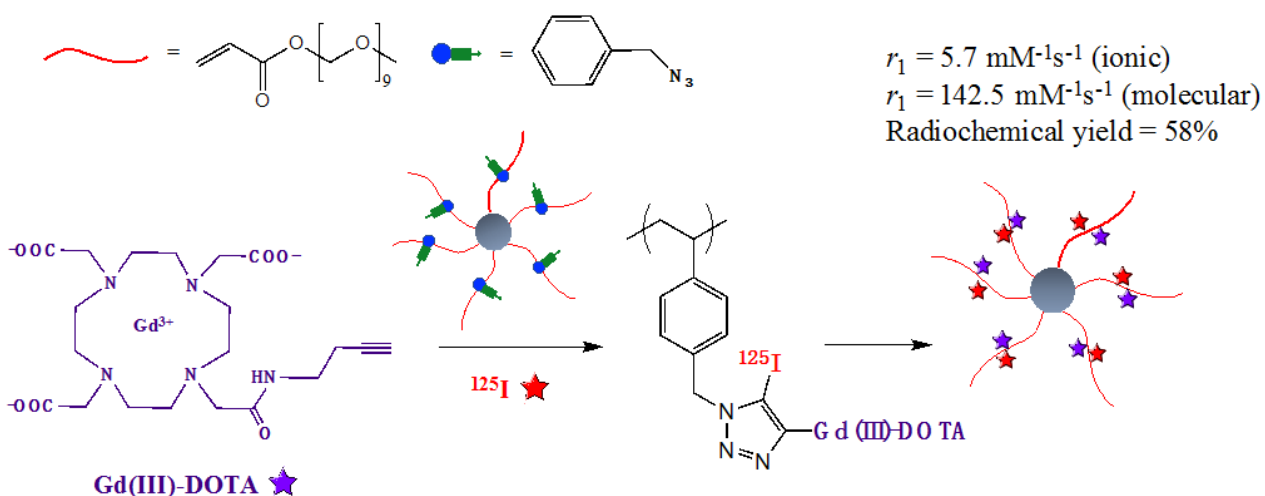

Figure 6. Synthetic strategy for the preparation of Gd(III)-DOTA star polymer NPs radiolabeled with ${ }^{125} \mathrm{I}$.

\section{Neutron Capture Therapy Combined with MRI}

The therapeutic nature of neutron beams was first proposed in 1936 [63] and two decades later was demonstrated experimentally as a binary modality known today as neutron capture therapy (NCT). This approach combines the features of both internal- and external radiotherapies: in the first step, the patient is injected intravenously (IRT) with a non-radioactive compound that accumulates in the tumor, and then externally irradiated (ERT) with epithermal neutrons in the second step. The principle relies on the ability of selected stable isotope to capture neutrons due to cross-sections many times higher than those of naturally present tissue elements. One of the successful applications of this methodology is boron neutron capture therapy (BNCT) that exploits non-radioactive isotope ${ }^{10} \mathrm{~B}(20 \%$ natural abundance). Capturing of neutrons by ${ }^{10} \mathrm{~B}$ yields excited ${ }^{11} \mathrm{~B}^{*}$ that undergoes nuclear fission reaction releasing high linear energy transfer (LET) $\alpha$-particles $\left({ }^{4} \mathrm{He}\right)$ and recoiling ${ }^{7} \mathrm{Li}$ nuclei, two products within the range of the cell diameter $(5-10 \mu \mathrm{m})$ (Figure 7A). The efficacy of the therapy is to a great extent determined by the concentration of selectively delivered boron atoms: typically $\sim 10^{9}$ atoms/cell (or lower if located close to the cell nucleus) [64]. In cases where the critical boron concentration is not reached, irradiation of the patient will only lead to undesired side-effects due to neutron capturing by endogenous elements, such as nitrogen and hydrogen. Sufficient retention at the tumor during the treatment, tumor-to-healthy tissues (3:1) and tumor-to-blood ratios (5:1), as well as adequate lipophilicity for efficient cross-over of the blood-brain barrier (BBB) and safe clearance, are other restrains for a successful BNCT probe. Provided that these conditions are met, the radiation dose to the tumor cells will be much higher than that in the surrounding health tissues, which renders BNCT especially suitable for locally dispersed tumors.

Boron delivery agents have passed through considerable development over the years [65]. The first generation of simple borax compounds caused severe adverse effects, which could be slightly improved in the case of polyhedral decahydrodecaborate (Figure 7B), but the selectivity of these compounds towards tumors remained poor. Better results in terms of toxicity and specificity were achieved later with ${ }^{10} \mathrm{~B}$-enriched sodium mercaptoundecahydro-closo-dodecaborate (BSH) and L-boronophenylalanine 
(L-BPA), both applied in clinical trials. The latter compound has also been formulated as a complex with a fructose molecule for better solubility in water.

The search for a proper BNCT agent, however, has still not reached its optimum, which certainly hampers the application of this otherwise attractive therapeutic technique. Therefore, the possibility to evaluate the in vivo kinetics of potential BNCT agents by means of high-resolution imaging represents a valuable asset. The first attempts to visualize the process was made by radiolabeling of BPA with ${ }^{18} \mathrm{~F}$ for simultaneous PET imaging [66]. However, this method had disadvantages due to limited availability of the tracer and low resolution of PET. Therefore, conjugation of MRI reporters with either polyhedral or BPA boron-containing fragments represents a more elegant approach. One of the early examples of this approach is a Mn(II)-porphyrin complex bearing four carborane moieties (Mn(II)-BOPP, Figure 7C) [67]. The compound showed a good in vivo affinity towards gliomas and enabled assessment of biodistribution by $T_{1}$-weighted MR imaging. Another group has exploited Gd(III)-DTPA complex for conjugation with both BPA and carborane functionalities for in vivo delivery of boron species to a hepatoma tumor that could be followed by MRI [68]. However, the biodistribution of the conjugates appeared unfavorable compared to the native BNCT agents and the resulting boron concentration in the cells not sufficient for therapy. This problem was tacked later by the design of Gd(III)-DOTA-carborane (Figure 7C) with increased molecular weight due to supramolecular assembly with $\beta$-cyclodextrin and the consequent $r_{1}$ relaxivity of $15.5 \mathrm{mM}^{-1} \cdot \mathrm{s}^{-1}$ at $20 \mathrm{MHz}$. The therapeutic advantage of the probe was demonstrated by its ability to deliver up to $35 \mu \mathrm{g}$ of boron per gram of B16 melanoma tissue within $4 \mathrm{~h}$ p.i. and the subsequent decreased tumor growth after neutron irradiation.

An additional advantage of $\mathrm{Gd}$, next to its superior paramagnetic properties, is the high neutron absorption cross-section of two of its natural isotopes ${ }^{155} \mathrm{Gd}$ and ${ }^{157} \mathrm{Gd}$, with the value for the latter (255,000 barns) being $65 \times$ higher than that of ${ }^{10} \mathrm{~B}$. As the result, the same amount of $\mathrm{Gd}$ delivered to the tumor cells would result in a much higher rate of neutron absorption reactions, or better to say, the same therapeutic outcome could be reached with a lower integrated thermal flux and/or lower concentrations of the probe applied. Moreover, the delivery process can be monitored by MRI, which allows for personalized irradiation of the patients. Despite these benefits, Gd-NCT has not reached the clinics mainly due to secondary radiation effects intrinsically different than those in BNCT. The neutron capturing reaction of ${ }^{157} \mathrm{Gd}$ leads to excited ${ }^{158} \mathrm{Gd}^{*}$ accompanied with prompt $\gamma$-rays emission and inner-shell transitions that in turn generate Auger electrons and X-rays (Figure 7A). The high energy of prompt $\gamma$ affect tissues in the range of several tens of $\mathrm{cm}$, which can be seen as a drawback reducing the selectivity of Gd-NCT. On the other hand, the energy deposition of the prompt $\gamma$ is much less in comparison to the dose delivered by Auger electrons, which results in double-stranded DNA breaks, provided that ${ }^{157} \mathrm{Gd}$ is deposited in the direct proximity of the nucleus or other vital organelles with the effective concentration of $200 \mu \mathrm{g} / \mathrm{g}$ of tumor tissues. These considerations require even more careful design of the agents for successful therapies, as extensively reviewed in the literature [69].

An obvious choice for the Gd-containing agents for Gd-NCT would be MRI CAs that already exist in the clinic if not their unspecific nature towards the tumors. Several groups have reported on the in vivo therapeutic effect of Gd(III)-DTPA upon neutron irradiation of tumors either after continuous infusion [70] or intratumoral administration [71] of the agent. An improved intravenous delivery of ${ }^{157} \mathrm{Gd}$ (up to $800 \mu \mathrm{g}$ ) with a favorable brain tumor/normal tissue ratio could be achieved with Gd(III)-EDTMP (ethylenediaminetetrabismethylenephosphonate)—a phosphonated ethylenediaminetetraacetic acid (EDTA)-analogue [72]. However, all these attempts only confirmed the prerequisite for not only the specificity of the agents towards tumors, but also their prolonged retention during irradiation sessions. From this perspective, encapsulation of Gd-complexes into nanoparticulate systems offers a possibility for intravenous delivery of high-payloads of Gd to the tumors based on either EPR effect or conjugation with targeting vectors; both approaches have been worked out extensively for MRI. For instance, loading of Gd(III)-DTPA into chitosan nanoparticles [73] or calcium phosphate micelles [74] resulted in enhanced accumulation of the probe after intratumoral 
injection was accompanied with significant reduction of tumor grows under localized MRI contrast compared to Gd(III)-DTPA alone.

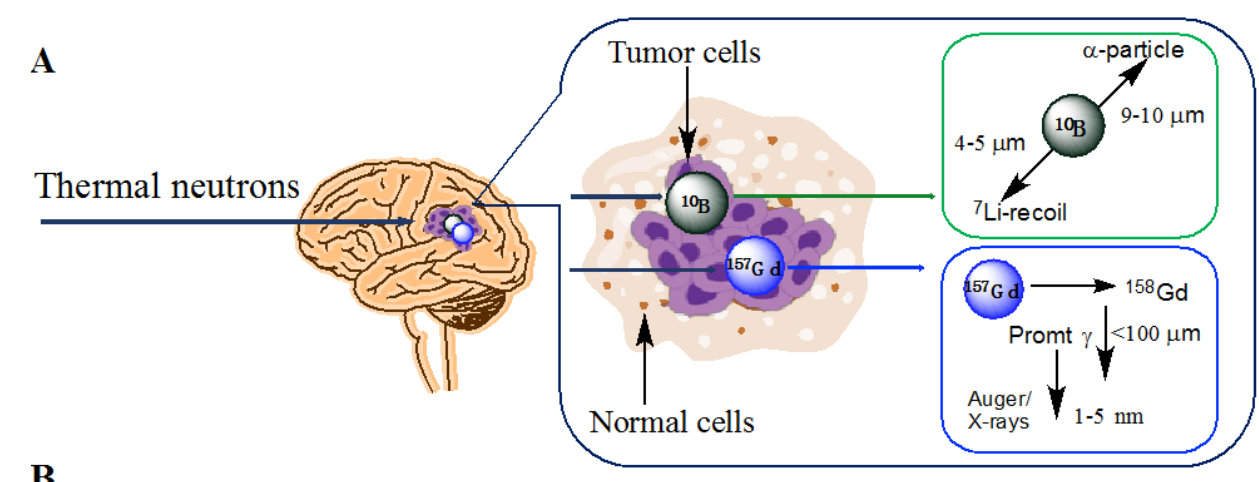

B<smiles>O=BOB([O-])OB(OB=O)OB=O</smiles>

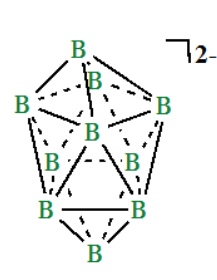<smiles>N[C@H](Cc1ccc(B(O)O)cc1)C(=O)O</smiles>
Borax Pentaborate Decahydrodecarborate

$\mathrm{BSH}$

L-BPA

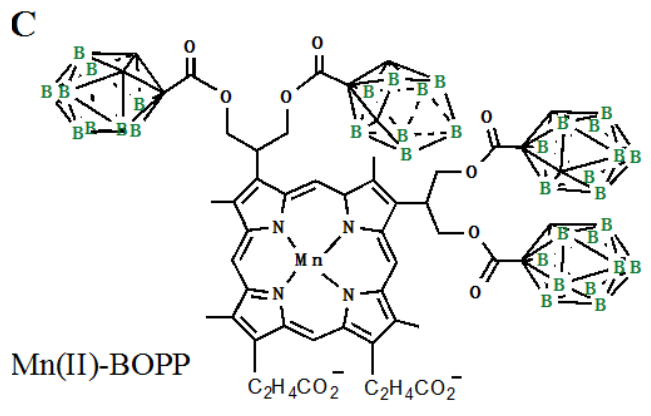

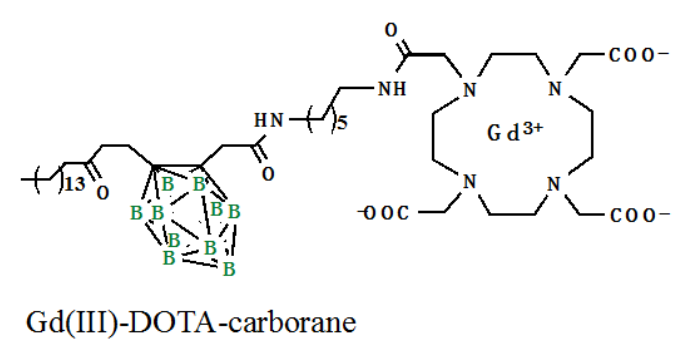

Figure 7. Principles and agents for boron and gadolinium neutron capture therapy (NCT): (A) Schematic representation of boron and gadolinium neutron capture reaction; (B) first drugs for boron neutron capture therapy (BNCT); (C) examples of probes for combined MR imaging and BNCT.

\section{Conclusions}

Translation of MRI-assisted radiotherapy into the clinic requires interdisciplinary efforts taking into account the beneficial aspects of each modality as well as the limitations and challenges. Due to its non-invasive nature and high soft-tissue resolution, MRI has already established itself as a good alternative to CT imaging that can offer complementary information in RTP. On the other hand, increased involvement of MRI during actual RT will eventually depend on the instrumental progress in integration of linear accelerators and MRI scanners and development of new treatment modalities such as image-guided brachytherapy, which will ultimately lead to expansion of the research towards MRI-based radiotheranostics. The already existing examples of such probes discussed in this review highlight the advantages of imaging for RT by enhancing the accuracy of the treatment relying on determination of the correct values of the delivered doses, the right timing for irradiation, and the possibility to follow the therapeutic effects in time. Maximization of the therapeutic effect was shown to be reached through additional assets such as radiosensitization, simultaneous hyperthermia, or the presence of an external magnetic field. These methodologies can profit from the versatile properties of NPs. In general, the preference to nanoparticular systems with high relaxivities and the simultaneous ability to either serve as radiosensitizer or carry various radiotherapeutic functionalities is clearly 
identified. The small size in combination with high surface-to-volume ratio, the possibility for facile surface functionalization, and the capacity for high-payload of imaging reporters render NPs very attractive for radiotheranostic applications. Delivery of NPs can be realized through either passive (EPR) of active (conjugation of specific vectors) targeting, while the administration route is an important parameter determining the biodistribution. A drawback in case of intravenous injection of NPs is their removal from the circulation by the monoclonal phagocytosis with $80 \%$ deposition in the liver Kupffer cells. Thereby, the negative surface charges of NPs increase hepatic uptake, while neutral charges increase blood-circulation time. Intratumoral administration of radiotherapeutic NPs, with additional MRI enhancing properties as a good alternative for brachytherapy, will obviously require careful study of tumor microenvironments in order to functionalize NPs in accordance with the therapeutic objective and the best imaging performance. In the case of SPIONs, the intracellular uptake typically results in their metabolization into lysosomes and release of non-superparamagnetic iron ions, which then undergo intrinsic iron metabolic pathways. However, elevated blood concentrations of iron may lead to severe anaphylactic reactions, which has mainly been the reason for the withdrawal of SPIONs from clinics. Therefore, the aspects such as non-specific accumulation, toxicity, long-term deposition, decomposition and eventual elimination of NPs are the most important challenges to be tackled during the design of MRI nanoprobes for radiotherapy, even if their properties for imaging and therapeutic efficiency seem to be satisfactory.

Author Contributions: All authors contributed equally to the writing process of this review.

Funding: This research received no external funding.

Acknowledgments: RPF thanks the Indonesia Endowment Fund for Education (LPDP) for the financial support.

Conflicts of Interest: The authors declare no conflict of interest.

\section{References}

1. Gaddikeri, S.; Gaddikeri, R.S.; Tailor, T.; Anzai, Y. Dynamic contrast-enhanced MR imaging in head and neck cancer: Techniques and clinical applications. Am. J. Neuroradiol. 2016, 37, 588-595. [CrossRef] [PubMed]

2. Hoskin, P.J.; Carnell, D.M.; Taylor, N.J.; Smith, R.E.; Stirling, J.J.; Daley, F.M.; Saunders, M.I.; Bentzen, S.M.; Collins, D.J.; d'Arcy, J.A.; et al. Hypoxia in prostate cancer: Correlation of BOLD-MRI with pimonidazole immunohistochemistry-Initial observations. Int. J. Radiat. Oncol. Biol. Phys. 2007, 68, 1065-1071. [CrossRef] [PubMed]

3. Bostel, T.; Nicolay, N.H.; Grossmann, J.G.; Mohr, A.; Delorme, S.; Echner, G.; Haring, P.; Debus, J.; Sterzing, F. MR-guidance-A clinical study to evaluate a shuttle-based MR-linac connection to provide MR-guided radiotherapy. Radiat. Oncol. 2014, 9, 12. [CrossRef] [PubMed]

4. Raaymakers, B.W.; Lagendijk, J.J.W.; Overweg, J.; Kok, J.G.M.; Raaijmakers, A.J.E.; Kerkhof, E.M.; van der Put, R.W.; Meijsing, I.; Crijns, S.P.M.; Benedosso, F.; et al. Integrating a 1.5T MRI scanner with a $6 \mathrm{MV}$ accelerator: Proof of concept. Phys. Med. Biol. 2009, 54, N229-N237. [CrossRef] [PubMed]

5. Torresin, A.; Brambilla, M.G.; Monti, A.F.; Moscato, A.; Brockmann, M.A.; Schad, L.; Attenberger, U.I.; Lohr, F. Review of potential improvements using MRI in the radiotherapy workflow. Z. Med. Phys. 2015, 25, 210-220. [CrossRef]

6. Kelkar, S.S.; Reineke, T.M. Theranostics: Combining imaging and therapy. Bioconj. Chem. 2011, 22, 1879-1903. [CrossRef]

7. Veldeman, L.; Madani, I.; Hulstaert, F.; De Meerleer, G.; De Meerleer, G.; De Neve, W. Evidence behind use of intensity-modulated radiotherapy: A systematic review of comparative clinical studies. Lancet Oncol. 2008, 9, 367-375. [CrossRef]

8. Emami, B.; Sethi, A.; Petruzzelli, G.J. Influence of MRI on target volume delineation and IMRT planning in nasopharyngeal carcinoma. Int. J. Radiat. Oncol. Biol. Phys. 2003, 57, 481-488. [CrossRef]

9. Caffo, O. Radiosensitization with chemotherapeutic agents. Lung Cancer 2001, 34 (Suppl. 4), S81-S90. [CrossRef]

10. Wardman, P. Chemical radiosensitizers for use in radiotherapy. Clin. Oncol. 2007, 19, 397-417. [CrossRef] 
11. Castillo, M.H.; Button, T.M.; Doerr, R.; Homs, M.I.; Pruett, C.W.; Pearce, J.I. Effects of radiotherapy on mandibular reconstruction plates. Am. J. Surg. 1988, 156, 261-263. [CrossRef]

12. Matsudaira, H.; Ueno, A.M.; Furuno, I. Iodine contrast medium sensitizes cultured mammalian cells to $X$ rays but not to $\gamma$ rays. Radiat. Res. 1980, 84, 144-148. [CrossRef]

13. Ngoune, R.; Peters, A.; von Elverfeldt, D.; Winkler, K.; Pütz, G. Accumulating nanoparticles by EPR: A route of no return. J. Control. Release 2016, 238, 58-70. [CrossRef] [PubMed]

14. Jokerst, J.V.; Lobovkina, T.; Zare, R.N.; Gambhir, S.S. Nanoparticle PEGylation for imaging and therapy. Nanomedicine 2011, 6, 715-728. [CrossRef]

15. Hainfeld, J.F.; Slatkin, D.N.; Smilowitz, H.M. The use of gold nanoparticles to enhance radiotherapy in mice. Phys. Med. Biol. 2004, 49, N309-N315. [CrossRef]

16. Tóth, E.; Helm, L.; Merbach, A. Relaxivity of Gadolinium(III) Complexes: Theory and Mechanism; John Wiley \& Sons Ltd.: Chichester, UK, 2013; pp. 25-81.

17. Zhang, B.; Liang, L.; Chen, W.; Liang, C.; Zhang, S. An updated study to determine association between gadolinium-based contrast agents and nephrogenic systemic fibrosis. PLoS ONE 2015, 10, e0129720. [CrossRef]

18. Vergauwen, E.; Vanbinst, A.-M.; Brussaard, C.; Janssens, P.; De Clerck, D.; Van Lint, M.; Houtman, A.C.; Michel, O.; Keymolen, K.; Lefevere, B.; et al. Central nervous system gadolinium accumulation in patients undergoing periodical contrast MRI screening for hereditary tumor syndromes. Hered. Cancer Clin. Pract. 2018, 16, 2. [CrossRef]

19. Thomas, S.R.; Khuntia, D. Motexafin gadolinium: A promising radiation sensitizer in brain metastasis. Expert Opin. Drug Dis. 2011, 6, 195-203. [CrossRef]

20. Richards, G.M.; Mehta, M.P. Motexafin gadolinium in the treatment of brain metastases. Expert Opin. Pharmacother. 2007, 8, 351-359. [CrossRef]

21. Thiabaud, G.; McCall, R.; He, G.; Arambula, J.F.; Siddik, Z.H.; Sessler, J.L. Frontispiece: Activation of platinum(IV) prodrugs by motexafin gadolinium as a redox mediator. Angew. Chem. Int. Ed. 2016, 55, 12626-12631. [CrossRef] [PubMed]

22. Botta, M.; Tei, L. Relaxivity enhancement in macromolecular and nanosized GdIII-based MRI contrast agents. Eur. J. Inorg. Chem. 2012, 2012, 1945-1960. [CrossRef]

23. Bazzi, R.; Flores, M.A.; Louis, C.; Lebbou, K.; Zhang, W.; Dujardin, C.; Roux, S.; Mercier, B.; Ledoux, G.; Bernstein, E.; et al. Synthesis and properties of europium-based phosphors on the nanometer scale: $\mathrm{Eu}_{2} \mathrm{O}_{3}$, $\mathrm{Gd}_{2} \mathrm{O}_{3}: \mathrm{Eu}$, and $\mathrm{Y}_{2} \mathrm{O}_{3}:$ Eu. J. Colloid. Interface Sci. 2004, 273, 191-197. [CrossRef]

24. Bridot, J.-L.; Dayde, D.; Riviere, C.; Mandon, C.; Billotey, C.; Lerondel, S.; Sabattier, R.; Cartron, G.; Le Pape, A.; Blondiaux, G.; et al. Hybrid gadolinium oxide nanoparticles combining imaging and therapy. J. Mater. Chem. 2009, 19, 2328-2335. [CrossRef]

25. Mignot, A.; Truillet, C.; Lux, F.; Sancey, L.; Louis, C.; Denat, F.; Boschetti, F.; Bocher, L.; Gloter, A.; Stéphan, O.; et al. A top-down synthesis route to ultrasmall multifunctional Gd-based silica nanoparticles for theranostic applications. Chem. Eur. J. 2013, 19, 6122-6136. [CrossRef]

26. Le Duc, G.; Roux, S.; Paruta-Tuarez, A.; Dufort, S.; Brauer, E.; Marais, A.; Truillet, C.; Sancey, L.; Perriat, P.; Lux, F.; et al. Advantages of gadolinium based ultrasmall nanoparticles vs. molecular gadolinium chelates for radiotherapy guided by MRI for glioma treatment. Cancer Nanotechnol. 2014, 5, 4. [CrossRef]

27. Bianchi, A.; Lux, F.; Tillement, O.; Crémillieux, Y. Contrast enhanced lung MRI in mice using ultra-short echo time radial imaging and intratracheally administrated Gd-DOTA-based nanoparticles. Magn. Res. Med. 2012, 70, 1419-1426. [CrossRef]

28. Detappe, A.; Thomas, E.; Tibbitt, M.W.; Kunjachan, S.; Zavidij, O.; Parnandi, N.; Reznichenko, E.; Lux, F.; Tillement, O.; Berbeco, R. Ultrasmall silica-based bismuth gadolinium nanoparticles for dual magnetic resonance-computed tomography image guided radiation therapy. Nano Lett. 2017, 17, 1733-1740. [CrossRef]

29. Du, F.; Zhang, L.; Zhang, L.; Zhang, M.; Gong, A.; Tan, Y.; Miao, J.; Gong, Y.; Sun, M.; Ju, H.; et al. Engineered gadolinium-doped carbon dots for magnetic resonance imaging-guided radiotherapy of tumors. Biomaterials 2017, 121, 109-120. [CrossRef]

30. Mahmoudi, M.; Hosseinkhani, H.; Hosseinkhani, M.; Boutry, S.; Simchi, A.; Journeay, W.S.; Subramani, K.; Laurent, S. Magnetic resonance imaging tracking of stem cells in vivo using iron oxide nanoparticles as a tool for the advancement of clinical regenerative medicine. Chem. Rev. 2011, 111, 253-280. [CrossRef] 
31. Laurent, S.; Forge, D.; Port, M.; Roch, A.; Robic, C.; Vander Elst, L.; Muller, R.N. Magnetic iron oxide nanoparticles: Synthesis, stabilization, vectorization, physicochemical characterizations, and biological applications. Chem. Rev. 2008, 108, 2064-2110. [CrossRef]

32. Revia, R.A.; Zhang, M. Magnetite nanoparticles for cancer diagnosis, treatment, and treatment monitoring: Recent advances. Mater. Today 2016, 19, 157-168. [CrossRef]

33. Kohler, N.; Sun, C.; Fichtenholtz, A.; Gunn, J.; Fang, C.; Zhang, M. Methotrexate-immobilized poly(ethylene glycol) magnetic nanoparticles for MR imaging and drug delivery. Small 2006, 2, 785-792. [CrossRef]

34. Medarova, Z.; Pham, W.; Kim, Y.; Dai, G.P.; Moore, A. In vivo imaging of tumor response to therapy using a dual-modality imaging strategy. Int. J. Cancer 2006, 118, 2796-2802. [CrossRef] [PubMed]

35. Saberi, A.; Shahbazi-Gahrouei, D.; Abbasian, M.; Fesharaki, M.; Baharlouei, A.; Arab-Bafrani, Z. Gold nanoparticles in combination with megavoltage radiation energy increased radiosensitization and apoptosis in colon cancer HT-29 cells. Int. J. Radiat. Biol. 2017, 93, 315-323. [CrossRef]

36. Khoshgard, K.; Kiani, P.; Haghparast, A.; Hosseinzadeh, L.; Eivazi, M.T. Radiation dose rate affects the radiosensitization of MCF-7 and HeLa cell lines to X-rays induced by dextran-coated iron oxide nanoparticles. Int. J. Radiat. Biol. 2017, 93, 757-763. [CrossRef]

37. Khoei, S.; Mahdavi, S.R.; Fakhimikabir, H.; Shakeri-Zadeh, A.; Hashemian, A. The role of iron oxide nanoparticles in the radiosensitization of human prostate carcinoma cell line DU145 at megavoltage radiation energies. Int. J. Radiat. Biol. 2014, 90, 351-356. [CrossRef]

38. Klein, S.; Sommer, A.; Distel, L.V.; Neuhuber, W.; Kryschi, C. Superparamagnetic iron oxide nanoparticles as radiosensitizer via enhanced reactive oxygen species formation. Biochem. Biophys. Res. Commun. 2012, 425, 393-397. [CrossRef] [PubMed]

39. Kirakli, E.K.; Takan, G.; Hoca, S.; Müftüler, F.Z.B.; Kılçar, A.Y.; Kamer, S.A. Superparamagnetic iron oxide nanoparticle (SPION) mediated in vitro radiosensitization at megavoltage radiation energies. J. Radioanal. Nucl. Chem. 2018, 315, 595-602. [CrossRef]

40. Rajaee, A.; Wensheng, X.; Zhao, L.; Wang, S.; Liu, Y.; Wu, Z.; Wang, J.; Si-Shen, F. Multifunctional bismuth ferrite nanoparticles as magnetic localized dose enhancement in radiotherapy and imaging. J. Biomed. Nanotechnol. 2018, 14, 1159-1168. [CrossRef] [PubMed]

41. Zhao, D.; Sun, X.; Tong, J.; Ma, J.; Bu, X.; Xu, R.; Fan, R. A novel multifunctional nanocomposite C225-conjugated $\mathrm{Fe}_{3} \mathrm{O}_{4} / \mathrm{Ag}$ enhances the sensitivity of nasopharyngeal carcinoma cells to radiotherapy. Acta Biochim. Biophys. Sin. 2012, 44, 678-684. [CrossRef] [PubMed]

42. Dou, Y.; Li, X.; Yang, W.; Guo, Y.; Wu, M.; Liu, Y.; Li, X.; Zhang, X.; Chang, J. Pb@Au core-satellite multifunctional nanotheranostics for magnetic resonance and computed tomography imaging in vivo and synergetic photothermal and radiosensitive therapy. ACS Appl. Mater. Interfaces 2017, 9, 1263-1272. [CrossRef]

43. Daou, T.J.; Grenèche, J.M.; Pourroy, G.; Buathong, S.; Derory, A.; Ulhaq-Bouillet, C.; Donnio, B.; Guillon, D.; Begin-Colin, S. Coupling agent effect on magnetic properties of functionalized magnetite-based nanoparticles. Chem. Mater. 2008, 20, 5869-5875. [CrossRef]

44. Longmire, M.; Choyke, P.L.; Kobayashi, H. Clearance properties of nano-sized particles and molecules as imaging agents: Considerations and caveats. Nanomedicine 2008, 3, 703-717. [CrossRef]

45. Zagar, T.M.; Oleson, J.R.; Vujaskovic, Z.; Dewhirst, M.W.; Craciunescu, O.I.; Blackwell, K.L.; Prosnitz, L.R.; Jones, E.L. Hyperthermia combined with radiation therapy for superficial breast cancer and chest wall recurrence: A review of the randomised data. Int. J. Hyperther. 2010, 26, 612-617. [CrossRef]

46. Kratochwil, C.; Bruchertseifer, F.; Giesel, F.L.; Weis, M.; Verburg, F.A.; Mottaghy, F.; Kopka, K.; Apostolidis, C.; Haberkorn, U.; Morgenstern, A. ${ }^{225}$ Ac-psma-617 for PSMA-targeted alpha-radiation therapy of metastatic castration-resistant prostate cancer. J. Nucl. Med. 2016, 57, 1941-1944. [CrossRef]

47. Yeong, C.-H.; Cheng, M.-H.; Ng, K.-H. Therapeutic radionuclides in nuclear medicine: Current and future prospects. J. Zhejiang Univ. Sci. B 2014, 15, 845-863. [CrossRef]

48. Carvalho, D.P.; Ferreira, A.C. The importance of sodium/iodide symporter (NIS) for thyroid cancer management. Arq. Bras. Endocrinol. Metabol. 2007, 51, 672-682. [CrossRef]

49. Srivastava, S.; Dadachova, E. Recent advances in radionuclide therapy. Semin. Nucl. Med. 2001, 31, 330-341. [CrossRef] 
50. D'Angelo, G.; Sciuto, R.; Salvatori, M.; Sperduti, I.; Mantini, G.; Maini, C.L.; Marian, G. Targeted "bone-seeking" radiopharmaceuticals for palliative treatment of bone metastases: A systematic review and meta-analysis. Q. J. Nucl. Med. Mol. Imaging 2012, 56, 538-543.

51. Dash, A.; Knapp, F.F.; Pillai, M.R. Targeted radionuclide therapy-An overview. Curr. Radiopharm. 2013, 6, 152-180. [CrossRef]

52. Pugh, T.J.; Pokharel, S.S. Magnetic resonance imaging in prostate brachytherapy: Evidence, clinical end points to data, and direction forward. Brachytherapy 2017, 16, 659-664. [CrossRef]

53. Bult, W.; Kroeze, S.G.C.; Elschot, M.; Seevinck, P.R.; Beekman, F.J.; de Jong, H.W.A.M.; Uges, D.R.A.; Kosterink, J.G.W.; Luijten, P.R.; Hennink, W.E.; et al. Intratumoral administration of holmium-166 acetylacetonate microspheres: Antitumor efficacy and feasibility of multimodality imaging in renal cancer. PLoS ONE 2013, 8, e52178. [CrossRef]

54. Smits, M.L.J.; Elschot, M.; van den Bosch, M.A.A.J.; van de Maat, G.H.; van het Schip, A.D.; Zonnenberg, B.A.; Seevinck, P.R.; Verkooijen, H.M.; Bakker, C.J.; de Jong, H.W.A.M.; et al. In vivo dosimetry based on SPECT

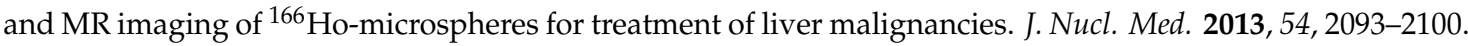
[CrossRef]

55. Van de Maat, G.H.; Seevinck, P.R.; Elschot, M.; Smits, M.L.J.; de Leeuw, H.; van het Schip, A.D.; Vente, M.A.D.; Zonnenberg, B.A.; de Jong, H.W.A.M.; Lam, M.G.E.H.; et al. MRI-based biodistribution assessment of holmium-166 poly(L-lactic acid) microspheres after radioembolisation. Eur. Radiol. 2013, 23, 827-835. [CrossRef]

56. Cao, J.; Wang, Y.; Yu, J.; Xia, J.; Zhang, C.; Yin, D.; Häfeli, U.O. Preparation and radiolabeling of surface-modified magnetic nanoparticles with rhenium-188 for magnetic targeted radiotherapy. J. Magn. Magn. Mater. 2004, 277, 165-174. [CrossRef]

57. Chunfu, Z.; Jinquan, C.; Duanzhi, Y.; Yongxian, W.; Yanlin, F.; Jiajü, T. Preparation and radiolabeling of human serum albumin (HSA)-coated magnetite nanoparticles for magnetically targeted therapy. Appl. Radiat. Isotopes 2004, 61, 1255-1259. [CrossRef]

58. Zhang, C.; Sun, H.; Xia, J.; Yu, J.; Yao, S.; Yin, D.; Wang, Y. Synthesis of polyacrylamide modified magnetic nanoparticles and radiolabeling with ${ }^{188}$ Re for magnetically targeted radiotherapy. J. Magn. Magn. Mater. 2005, 293, 193-198. [CrossRef]

59. Aslan, T.N.; Aşık, E.; Volkan, M. Preparation and labeling of surface-modified magnetoferritin protein cages with a rhenium(I) carbonyl complex for magnetically targeted radiotherapy. RSC Adv. 2016, 6, 8860-8869. [CrossRef]

60. Radović, M.; Calatayud, M.P.; Goya, G.F.; Ibarra, M.R.; Antić, B.; Spasojević, V.; Nikolić, N.; Janković, D.; Mirković, M.; Vranješ-Đurić, S. Preparation and in vivo evaluation of multifunctional ${ }^{90}$ Y-labeled magnetic nanoparticles designed for cancer therapy. J. Biomed. Mater. Res. A 2015, 103, 126-134. [CrossRef]

61. Chen, J.; Zhu, S.; Tong, L.; Li, J.; Chen, F.; Han, Y.; Zhao, M.; Xiong, W. Superparamagnetic iron oxide nanoparticles mediated ${ }^{131} \mathrm{I}$-hVGF siRNA inhibits hepatocellular carcinoma tumor growth in nude mice. BMC Cancer 2014, 14, 114. [CrossRef]

62. Esser, L.; Lengkeek, N.A.; Moffat, B.A.; Vu, M.N.; Greguric, I.; Quinn, J.F.; Davis, T.P.; Whittaker, M.R. A tunable one-pot three-component synthesis of an ${ }^{125} \mathrm{I}$ and Gd-labelled star polymer nanoparticle for hybrid imaging with MRI and nuclear medicine. Polym. Chem. 2018, 9, 3528-3535. [CrossRef]

63. Locher, G.L. Biological effects and therapeutic possibilities of neutrons. Am. J. Roentgenol. 1936, 36, 1-13.

64. Miyatake, S.-I.; Kawabata, S.; Hiramatsu, R.; Kuroiwa, T.; Suzuki, M.; Kondo, N.; Ono, K. Boron neutron capture therapy for malignant brain tumors. Neurol. Med. Chir. 2016, 56, 361-371. [CrossRef]

65. Barth, R.F.; Coderre, J.A.; Vicente, M.G.H.; Blue, T.E. Boron neutron capture therapy of cancer: Current status and future prospects. Clin. Cancer. Res. 2005, 11, 3987-4002. [CrossRef]

66. Kabalka, G.W.; Smith, G.T.; Dyke, J.P.; Reid, W.S.; Longford, C.D.; Roberts, T.G.; Kesavulu Reddy, N.; Buonocore, E.; Hübner, K.F. Evaluation of fluorine-18-BPA-fructose for boron neutron capture treatment planning. J. Nucl. Med. 1997, 38, 1762-1767.

67. Huang, L.R.; Straubinger, R.M.; Kahl, S.B.; Koo, M.-S.; Alletto, J.J.; Mazurchuk, R.; Chau, R.I.; Thamer, S.L.; Fiel, R.J. Boronated metalloporphyrins: A novel approach to the diagnosis and treatment of cancer using contrast-enhanced MR imaging and neutron capture therapy. J. Magn. Reson. Imaging 1993, 3, 351-356. [CrossRef] 
68. Takahashi, K.; Nakamura, H.; Furumoto, S.; Yamamoto, K.; Fukuda, H.; Matsumura, A.; Yamamoto, Y. Synthesis and in vivo biodistribution of BPA-Gd-DTPA complex as a potential MRI contrast carrier for neutron capture therapy. Bioorg. Med. Chem. 2005, 13, 735-743. [CrossRef]

69. Deagostino, A.; Protti, N.; Alberti, D.; Boggio, P.; Bortolussi, S.; Altieri, S.; Geninatti-Crich, S. Insights into the use of gadolinium and gadolinium/boron-based agents in imaging-guided neutron capture therapy applications. Future Med. Chem. 2016, 8, 899-917. [CrossRef]

70. Akine, Y.; Tokita, N.; Tokuuye, K.; Satoh, M.; Churei, H.; Le Pechoux, C.; Kobayashi, T.; Kanda, K. Suppression of rabbit VX-2 subcutaneous tumor growth by gadolinium neutron capture therapy. Jpn. J. Cancer Res. 1993, 84, 841-843. [CrossRef]

71. Khokhlov, V.F.; Yashkin, P.N.; Silin, D.I.; Djorova, E.S.; Lawaczeck, R. Neutron capture therapy with gadopentetate dimeglumine: Experiments on tumor-bearing rats. Acad. Radiol. 1995, 2, 392-398. [CrossRef]

72. Brugger, R.M.; Shih, J.A. Evaluation of gadolinium-157 as a neutron capture therapy agent. Strahlenther. Onkol. 1989, 165, 153-156.

73. Tokumitsu, H.; Hiratsuka, J.; Sakurai, Y.; Kobayashi, T.; Ichikawa, H.; Fukumori, Y. Gadolinium neutron-capture therapy using novel gadopentetic acid-chitosan complex nanoparticles: In vivo growth suppression of experimental melanoma solid tumor. Cancer Lett. 2000, 150, 177-182. [CrossRef]

74. Dewi, N.; Mi, P.; Yanagie, H.; Sakurai, Y.; Morishita, Y.; Yanagawa, M.; Nakagawa, T.; Shinohara, A.; Matsukawa, T.; Yokoyama, K.; et al. In vivo evaluation of neutron capture therapy effectivity using calcium phosphate-based nanoparticles as Gd-DTPA delivery agent. J. Cancer. Res. Clin. Oncol. 2016, 142, 767-775. [CrossRef]

(C) 2019 by the authors. Licensee MDPI, Basel, Switzerland. This article is an open access article distributed under the terms and conditions of the Creative Commons Attribution (CC BY) license (http://creativecommons.org/licenses/by/4.0/). 